\title{
Pembacaan Sinyal Otot Pada Wajah Dan Sekitar Kepala Menggunakan Sensor Elektromiografi
}

\author{
${ }^{1}$ Johanes Christo Adi Purnama*), ${ }^{1}$ Florentinus Budi Setiawan \\ 1Teknik Elektro, Universitas Katolik Soegijapranata \\ Johanes_christo@yahoo.com*)
}

\begin{abstract}
ABSTRAK
Pada jaman modern ini,Pada dunia teknologi sudah mengalami kemajuan sangat pesat.Diantaranya adalah di bidang biomedis. Di bidang biomedis terdapat alat yang bernama sensor Elektromiografi,yaitu sebuah alat yang dapat membaca sinyal pada otot manusia.Alat ini sangat banyak pengaplikasianya di dunia bio medis.Sensor Elektromiografi,yaitu sebuah alat yang dapat membaca sinyal pada otot manusia,Yang selanjutnya akan diolah sinyalnya untuk menghasilkan sebuah output tertentu.

Pada paper ini penulis melakukan pembacaan sinyal otot atau Elektromiografi menggunakan sensor Elektromiografi yang di inputkan ke Mikrokontroler AT MEGA 8535 untuk mengendalikan LCD sebagai tampilan dari hasil pengukuran tersebut.Sinyal yang di hasilkan dari prngukuran ini dapat digunakan juga untuk mengendalikan output dalam bentuk lain seperti contoh aplikasinya untuk mengendalikan lengan robot atau mengendalikan output dalam bentuk audio.
\end{abstract}

Kata Kunci : Elektromiografi ,Mikrikontroler AT MEGA $8535, L C D$

\section{PENDAHULUAN}

Pada kegiatan sehari-hari setiap orang menggunakan otot wajah ,contohnya untuk berbicara ,tersenyum,mengunyah dan masih banyak lainya.Namun pada dasarnya otot wajah dapat mengeluarkan pulsa elektronik dan dapat dibaca dengan menggunakan suatu sensor.Pembacaan pulsa elektronik pada otot wajah dapat di fungsikan untuk mengetahui seberapa besar pulsa elektronik yang terdapat pada suatu otot dan dapat difungsikan untuk mengendalikan keluaran dalam bentuk visual,audio,maupun mekanis.Dalam perkembangan nya pembacaan otot sendiri sudah di aplikasikan dalam beberapa alat seperti pembaca detak jatung lengan robot kaki robot dan masih banyak lainya.

Pada pembacaan sinyal otot sekitar wajah menggunakan elektroda ini dapat menghasilkan sinyal elektronik.Sinyal ini yang nantinya akan di deteksi lalu bisa digunakan untuk mengendalikan keluaran.Keluaran tersebut bisa dalam bentuk audio atau suara maupun dapat berbentuk mekanis.Rencana desain alat yang akan dibuat adalah ,dengan menggunakan sensor
EMG(Electromyography) yang merupakan elektroda yang akan di tempelkan ke otot lalu keluaran EMG ini akan menghasilkan pulsa elektronik,lalu akan di kuatkan oleh OP AMP dengan tipe AD8226.Setelah itu baru bisa di identifikasi lalu di gunakan untuk mengendalikan suatu keluaran/output.

\section{LANDASAN TEORI}

Sebelum membahas perancangan alat Elektromiografi penulis akan menjelaskan bagaimana terjadinya sinyal yang dihasilkan oleh otot manusia, asal mula terjadinya sinyal tegangan yang akan di baca oleh elektroda yang menempel pada permukaan kulit, sinyal dihasilkan dari proses Polarisasi dan Depolarisasi 2 Ion penting dalam sel-sel otot, Ion tersebut adalah Natrium $\left(\mathrm{Na}^{+}\right)$dan $\operatorname{Potasium}\left(\mathrm{K}^{+}\right)$, Proses terjadinya tegangan di bagi menjadi 3 bagian, yaitu Polarisasi (Penegangan otot) , Depolarisasi (Pelemasan otot), dan Kondisi istirahat.Dalam membaca sinyal yang dihasilkan oleh otot juga terdapat sebuah satuan yaitu MUAP (Motor Unit Action Potential).Maka dari teori diatas dapat diuat diagram,[5]

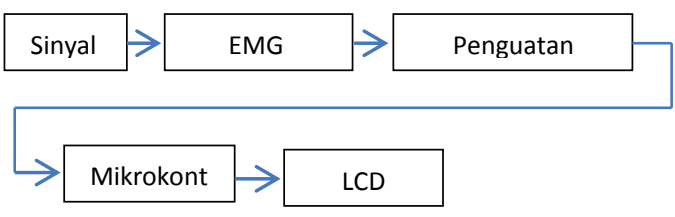

Gambar 1 Sistem kerja alat

\section{- Elektromiografi}

Elektromiografi adalah mengukur aktivitas otot melalui potensi listrik.Secara tradisional elektromiografi sudah diaplikasikan untuk penilitian medis dan diagnosis gangguan neuromuscular,namun pada perkembangan sekarang ini elektromiografi sudah di aplikasikan untuk prostethics,robotika,dan system control lainya.Cara kerja dari Elektromiografi yaitu dengan cara menguatkat sinyal yang terdeteksi oleh elektroda,setelah itu sinyal otot yang emiliki besaran sekian millivolt akan dikuatkan dengan suatu komponen yang bertipe AD8226 hingga sebesar 1000 
kali. Pada penelitian ini menggunakan modul electromiografi v3.Pada modul ini terdapat beberapa macamkomponen penting yaitu adalah penguat,filter,dan penyearah,dan EMG envelope. Modul ini juga menyediakan envelope detector. Envelope detector adalah sirkuit yang menggunakan input amplituda berfrekuensi tinggi dan menghasilkan output berupa titik-titik puncak yang dihasilkan oleh proses penguatan sebelumnya.

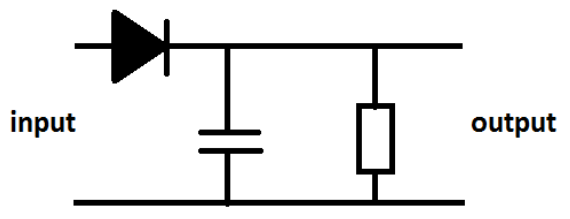

Gambar 2. Skematik Envelope Detector

Beberapa keuntungan dari modul elektromiografi v3 adalah modul ini dirancang untung digunakan langsung pada mikrokontroler,sehingga output dari sensor elektromiografi bukan EMG RAW tetapi sinyal yang sudah di perkuat, disearahkan dan diintegrasi,sehingga akan bekerja baik pada mikrokontroler dengan ADC (Analog Digital Converter).

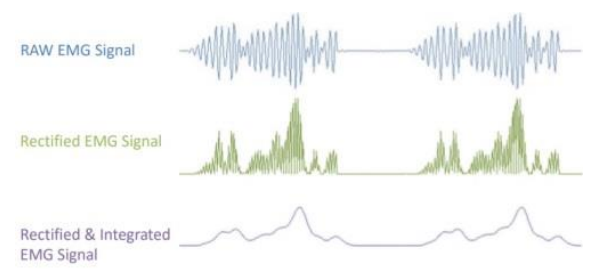

Gambar 3 Sinyal Output Modul Sensor Elektromiografi v3[2]

\section{PERANCANGAN ALAT}

Pada pengukuran dengan sensor Elektromiografi menggunakan modul muscle sensor v3.Dengan modul muscle sensor ini dikombinasikan dengan mikrokontroler untuk menampilkan data hasil dari pengukuran otot.Muscle sensor ini di fungsikan sebagai rangkaian analog sedangkan mikrokontroler difungsikan sebagai rangkaian digital.

\section{a. Rangakaian Analog}

Pada rangakaian ini Modul muscle sensor v3 di fungsikan sebagai rangkaian analog.Dalam modul muscle sensor ini terdapat beberapa komponen didlamnya yaitu penguat dengan tipe AD8266 dan filter dengan tipe TL084.Selain itu modul ini juga mempunyai envelope detector sehingga sinyal yang dihasikan bisa lebih baik bekerja pada ADC mikrokontroler.

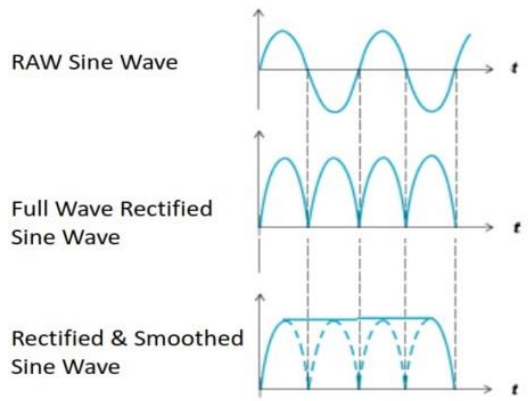

Gambar 4 Sinyal output dari Muscle sensor[2]

Gambar diatas adalah sinyal output dari muscle sensor yang sudah disearahkan dan sudah di integrasikan.
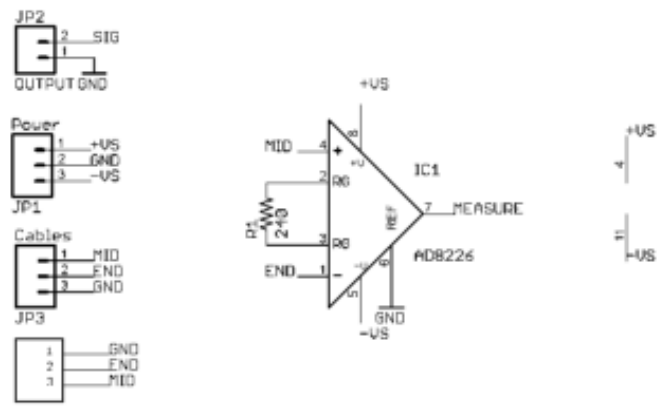

(a) Penguat AD8226

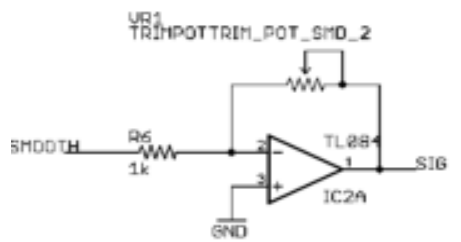

(b) Trimer TL 084

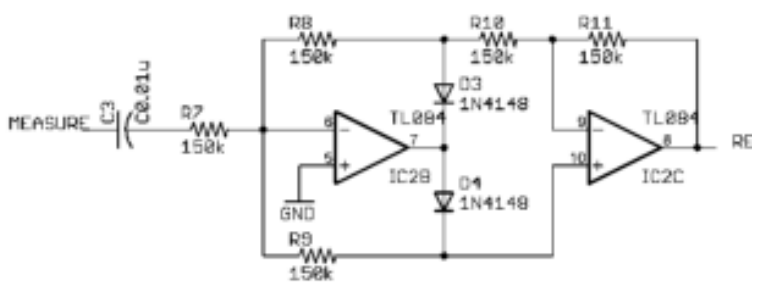

(c) Envelope detector 


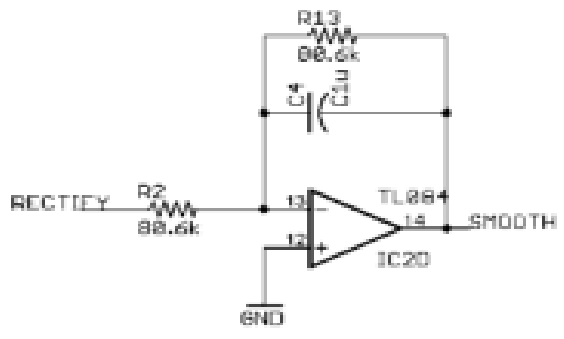

(d) Filter dan penintegrasi sinyal

Gambar 5 Rangkaian skematik pada muscle sensor[2]

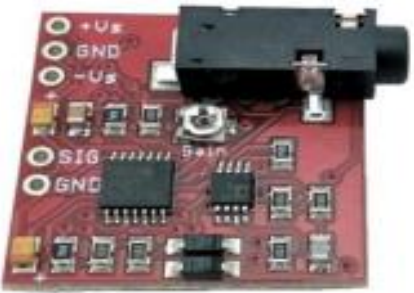

Gambar 6 Bentuk fisik muscle sensor v3[2]

Dari rangkaian diatas bisa kita dapatkan rumus penguata atau gain yang nantinya diaplikasikan untuk mencari penguatan pada sinyal otot

$$
\mathrm{G}=1+(49.4 \mathrm{k} \Omega / \mathrm{RG})
$$

\section{b. Rangkaian Digital}

Pada rangkaian digital mennggunakan Mikrokontroler ATMEGA 8535.Mikrokontroler ini memiliki 8 bit dengan kecepatan maksimal 16 Mhz.Mikrokontroler ini juga memiliki ADC pada salah satu portnya.berikut adalah konfigurasi pin dari mikrokontroler AT Mega 8535.

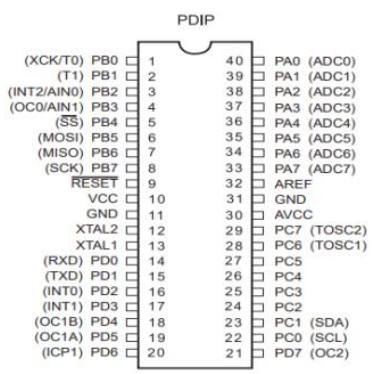

Gambar 7 Konfigurasi Pin[1]

Tentunya mikrokontroler ini memerlukan system minimum untuk membuatnya bekerja.Sistem minimum ini yang nanti akan menghubungkan ke rangkaian lain untuk menjalankan fungsi tertentu,dan juga system minimum ini yang akan dihubungkan suatu input atau output dari sebuah alat.

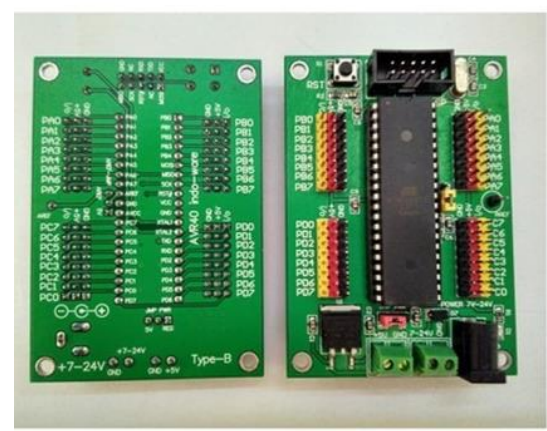

Gambar 7 Bentuk Fisik Sistem Minimum

\section{c. Elektroda}

Elektroda yang di gunakan dalam rangkaian ini adalah elektroda tipe gel, Alasan di pilih elektroda tipe gel adalah elektroda tersebut memiliki noise level yang lebih rendah daripada elektroda tipe perak klorida.

Elektroda juga merupakan komponen yang paling penting karena menjadi sarana masuknya sinyal dari permukaan kulit menuju AD8226 melalui konektor. 


\section{d. Software}

Tentunya dalam menjalankan fungsi suatu alat seuah mikrokontroler harus di program dengan sebuah program.Program inilah yang menjadi software dalam suatu alat.Sebalum membahas program yang akan di masukan ke mikrokontroler berikut adalah flow chart dari perintah program sensor Elektromiografi

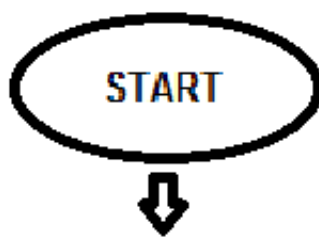

Inisialisasi

Variabel

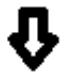

Inisialisasi-

Subprogram

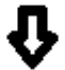

Inisialisasi \& Port

3

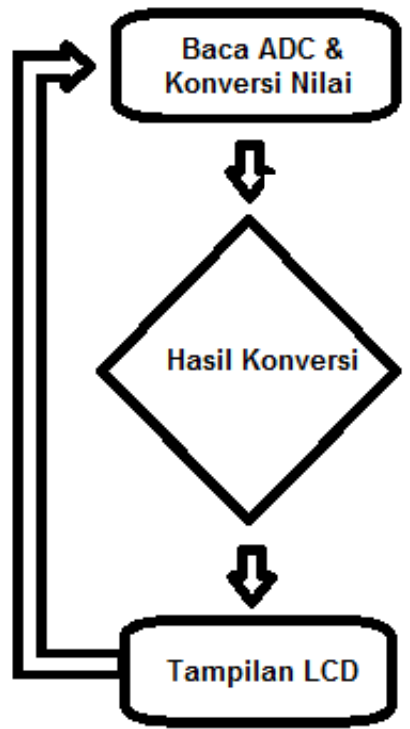

Dan berikut adalah Program yang dimasukan ke Mikrokontroler untuk menjalankan fungsi sebagai pengukuran sensor.

// LCD module initialization

$$
\text { lcd_init(16); }
$$

lcd_gotoxy $(0,0)$;

lcd_putsf("Pengukuran Otot Wajah"); delay_ms(500);

while (1)

\{

// Place your code here

dataADC=read_adc $(0)$;

Temp $=($ dataADC $* 4.9 / 10)$;

lcd_gotoxy $(0,0)$;

lcd_putsf("Elektro Unika");

lcd_gotoxy $(3,1)$;

lcd_putsf("0 mVOLT");

Temp=(dataADC*4.9/10);

lcd_gotoxy $(0,1)$;

tampil(Temp);

\}

\section{PENGUJIAN DAN HASIL}

Pengujian yang di lakukan dapat memberikan gambaran sinyal yang nantinya akan di olah lebih lanjut oleh mikrokontroler.

Sama seperti pada rancangannya, rangkaian dalam simulasi di sesuaikan dengan desain yang terdiri dari 3 buah Op-Amp yaitu AD8226 dan TL084, selain itu parameter lainnya juga di sesuaikan agar output Op-Amp hanya menghasilkan 5V agar mempermudah pengolahan sinyal dalam mikrokontrol, maka dari itu tegangan Op-Amp hanya di batasi di +/5Volt. 
Pada saat pengujian dilakukan pegukuran ke beberapa otot yaitu diantaranya adalah otot frontalis/dahi,otot pipi atau zygomaticus,otot belakang telinga atau sternocleidomastoideus.otot rahang atau masseter dan otot leher atau sternohyoideus berikut adalah titik titik pengukuran dan hasilnya

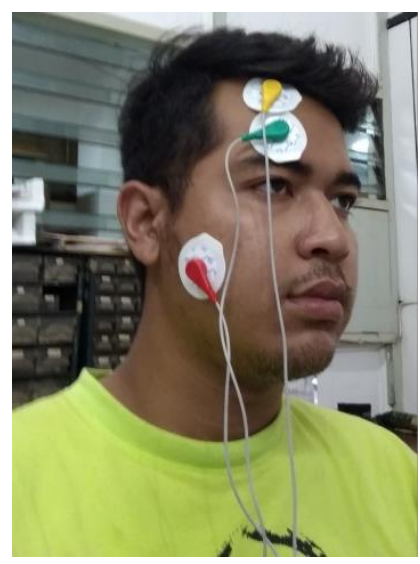

Gambar 9 Titik otot dahi atau frontalis

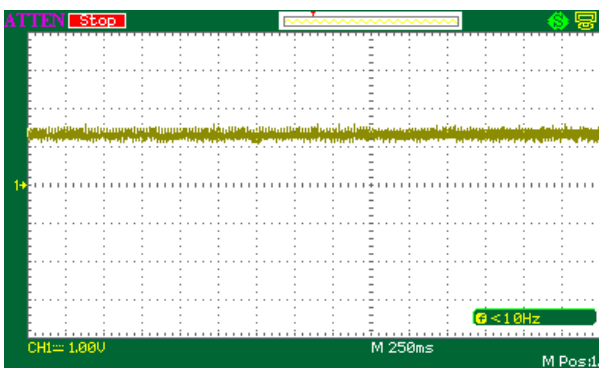

Gambar 10 Hasil sinyal dari Otot dahi

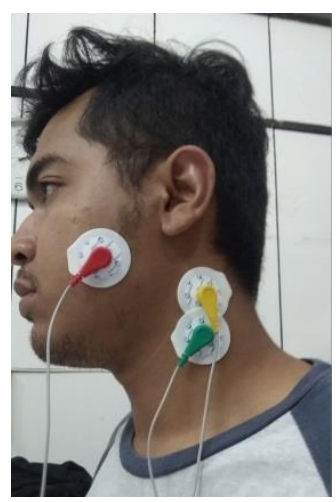

Gambar 11 Titik otot belakang telinga atau sternocleidomastoideus

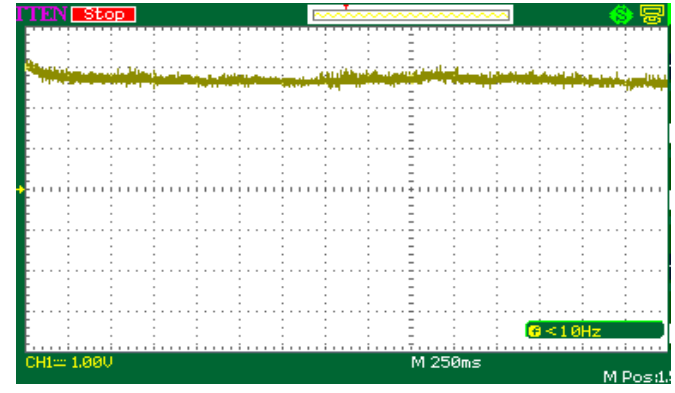

Gambar 12 Hasil sinyal dari otot belakang telinga atau sternocleidomastoideus

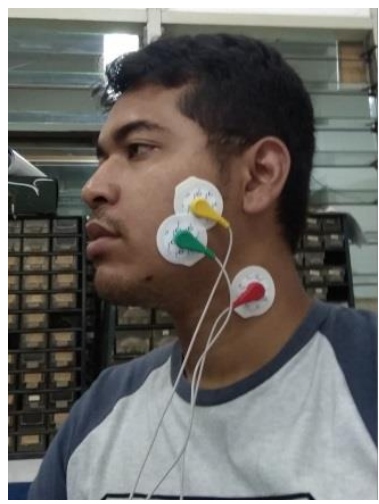

Gambar 13 Titik otot rahang atau maseter

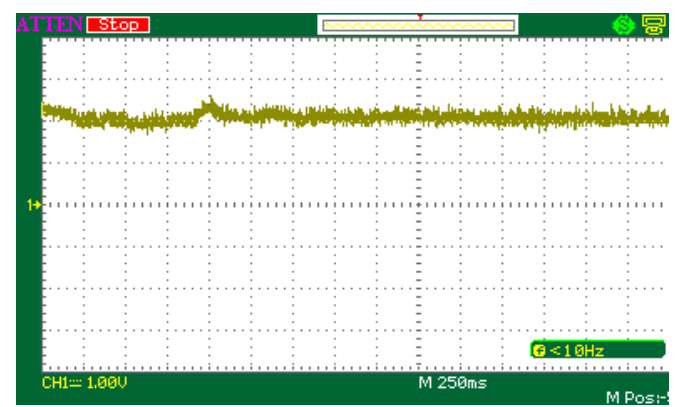

Gambar 14 Hasil sinyal otot rahang atau maseter

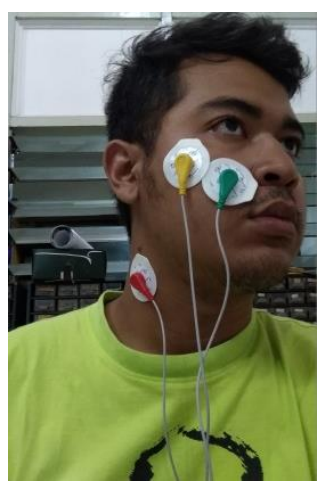

Gambar 15 Titik dari otot pipi atau zygomaticus 


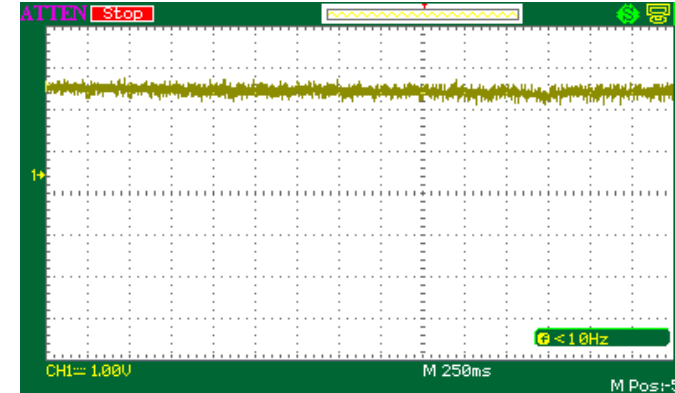

Gambar 16 Hasil dari otot pipi atau zygomaticus

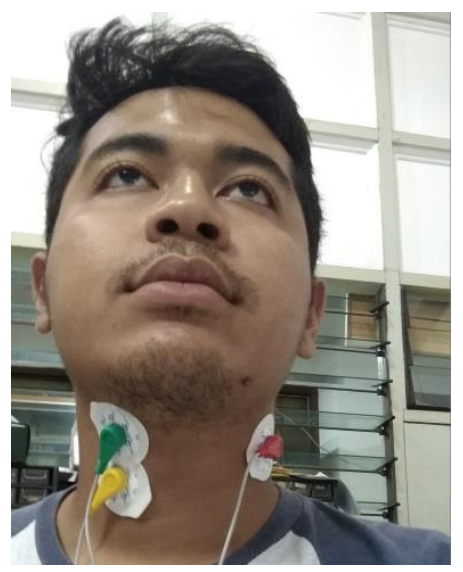

Gambar 17 Titik otot leher atau omohyioideus

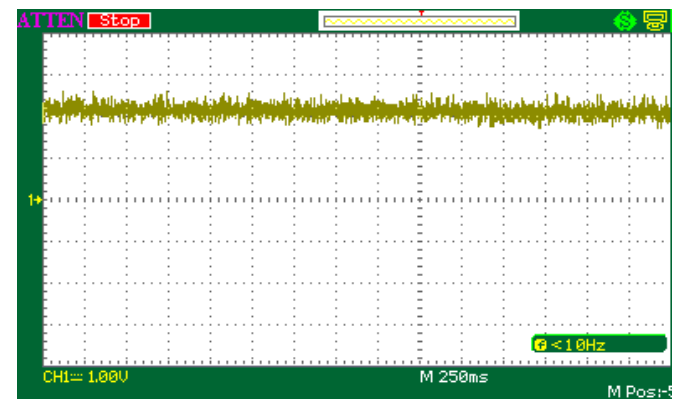

Gambar 18 Hasil otot leher atau omohyioideus

Diatas adalah titik dari beberapa otot yang diukur secara analog,pengukuran ini bedasarkan keluaran dari sensor Elektromiografi yang sudah di searahkan dan di integerasikan.

Disamping pengukuran secara analog dilakukan juga pengukuran secara digital yaitu mengukur keluaran dari sensor EMG yang sudah terolah dengan ADC dari mikrokontroler dan ditamplikan dengan LCD sebagai output dari mikrokontroler.Berikut adalah hasil dari beberapa pengukuran secara digital

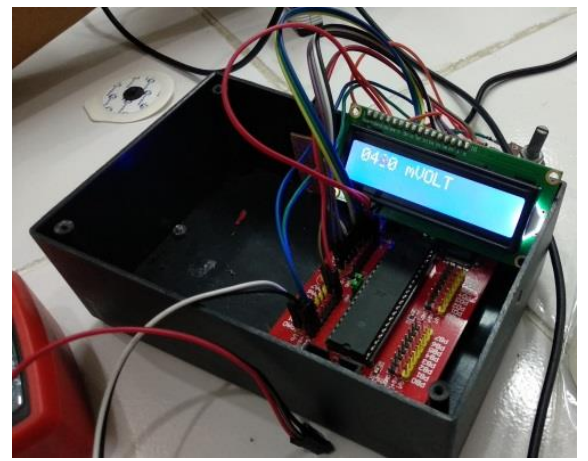

Gambar 19 Hasil dari salah satu otot sebelum ditegangkan

Pada hasil diatas adalah adalah hasil dari pengukuran salah satu otot,padaLCD menunjukan 0530 mVolt, memang pada kondisi otot belum di tegangkan tampilan LCD tidak akan menujukan hasil yang 0 sempurna dikarenakan keluaran dari sensor elektromiografi mendeteksi adanya tegangan kecil yang dikuatkan oleh AD822 dari sebuah otot,dan berikut adalah hasil dari pengukuran digital dari beberapa macam otot.

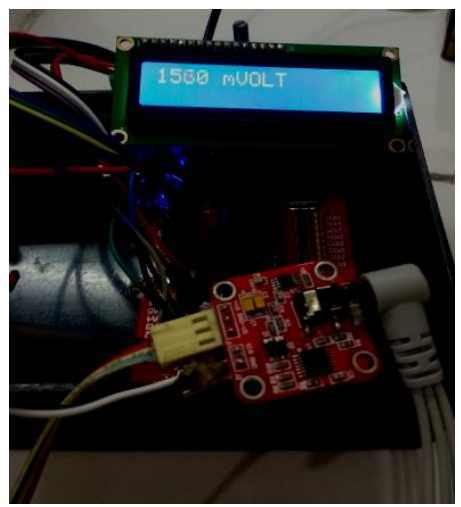

Gambar 20 Hasil dari otot frontalis atau dahi

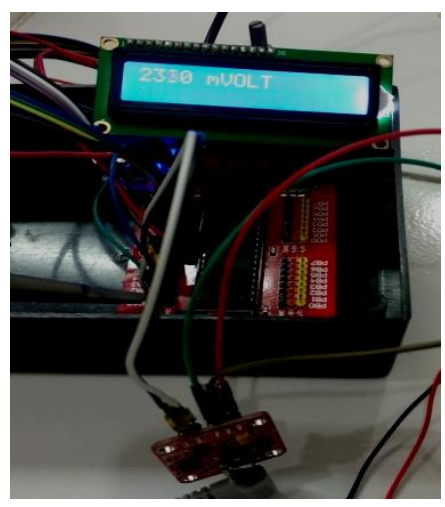

Gambar 21 Hasil dari pipi atau zygomaticus 


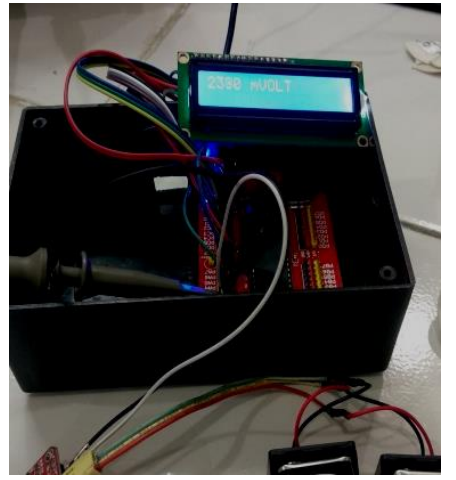

Gambar 22 Hasil otot belakang telinga

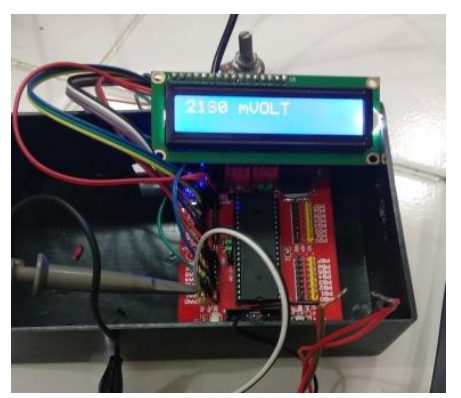

Gambar 23asil otot rahang atau masseter

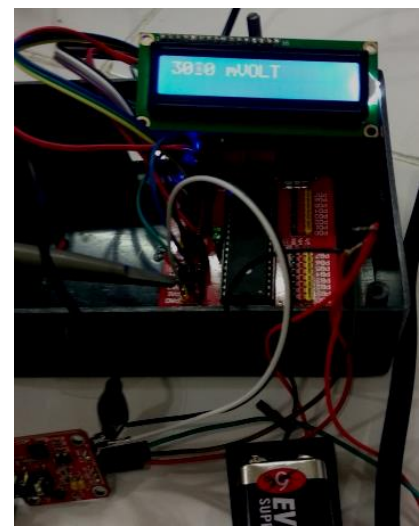

Gambar 24 Hasil otot leher atau omohyoideus

Jika diperhatikan hasil dari pengukuran beberapa otot yang ditunjukan oleh LCD angka yang dihasilkan berbeda beda saat di tegangkan dikarenakan oleh lapisan pada tiap tiap titik otot berbeda dan lapisan pada setiap orang juga berbeda terutama pada titik otot disekitar wajah.Otot pada wajah tidak sekuat otot pada tangan atau pada kaki jadi hasil yang di tamplikan juga rendah.Dan juga hasil yang di tampil kan pada hasil yang stuck atau diam dikarenakan pada saat ditegangkan otot tidak stabil pada kekuatan yang sama.

\section{KESIMPULAN DAN SARAN}

\subsection{Kesimpulan}

Setelah melakukan pengujian dan pengamatan telah didapatkan kesimpulan yang berdasarkan dari pengukuran sensor Elektromiografi yaitu:

1.Rangkaian analog dan digital pada pengukuran otot wajah dapat berfungsi dengan baik yaitu menguatkan sinyal yang dihasilkan otot untuk ditampilkan pada tampilan LCD

2.Program yang diinputkan pada mikrokontroler dapat berjalan dengan baik dan tepat dibuktikan menyamakan pengukaran dengan osiloskop dan nilai yang ditampilkan dari LCD

3. Nilai yang dihasilkan pada saat pengukuran berbeda beda dikarenakan lapisan lemak dan kekuatan pada tiap titik otot berbeda.Begitu juga otot pada setiap orang berbeda juga sinyal yang dihasilkan

4.Otot pada wajah juga bisa menghasilkan sinyal yang dapat di kuatkan dengan sensor Elektromiografi walapun sinyal yang dihasilkan tidak sekuat otot pada tangan dan kaki namun dapat terdeteksi dengan baik.

\subsection{Saran}

Pada alat ini masih dapat dikembangkan terutama pada output yang dihasilkan ,alat ini bisa dikembangkan dengan output audio dan mekanik,sebagai bentuk perkambangan dalam dunia biomedis,yang dapat membantu penderita difabel.

\section{DAFTAR PUSTAKA}

[1] Atmel.Datasheet AT Mega 8535 : AVR Mikrokontroller with $8 \mathrm{k}$ Bytes in-system programmable flash.

[2] Advancer technologies.Datasheet muscle sensor :Three- lead Drifferential Elektromiografi Sensor for Mikrokontrol

[3] Sellers, Bill. Introduction to EMG.http://machuwis.lut.ac.uk/ wis/lectures/

[4] Norali A.N,Mat Son M.H.Surface Elektromiography Signal Processing and review (Procceding of the international conference on man-machine system.2009)

[5] "Surface Electromyography: Detection and Recording," DelSysIncorporated, 1996 
[6] Analog Device,Data sheet AD 8226,Wide Supply Range, Rail-to-Rail Output Instrumentation Amplifier,2009

[7] Florentinus Budi Setiawan, Siswanto, "Multi Channel Electromyography (EMG) Signal”, Proc. of 2016 3rd Int. Conf. on Information Tech., Computer, and Electrical Engineering (ICITACEE), 2016.

[8] Florentinus Budi Setiawan, Siswanto, "Multi Channel Electromyography (EMG) Signal Acqiusition using Microcontroller with Rectifier", Proc. of 2016 3rd Int. Conf. on Information Tech., Computer, and Electrical Engineering (ICITACEE), 2016.

[9] Ricky Fajar Adiputra, Florentinus Budi Setiawan, "ROBOT ARM CONTROLLED BY MUSCLE TENSION BASED ON ELECTROMYOGRAPHY AND PIC18F4550", Proc. Of $20163^{\text {rd }}$ Int. Conf. on Information Tech., Computer, and Electrical Engineering (ICITACEE), 2016.

[10] Florentinus Budi Setiawan, Siswanto, "Electromyography (EM G) Signal Compression using Sinusoidal Segmental Model", Proc. of 2015 2nd Int. Conference on Information Technology, Computer and Electrical Engineering (ICITACEE), 2015.

[11] Analog Devices. 2003. "Low Cost Low Power Instrumentation Amplifier". One Technology Way.

[12] Kevin Eka Pramudita, F.Budi Setiawan, Siswanto, "Interface and display of Electromyography signal wireless measurements", $20141^{\text {st }}$ International Conference on Information Technology, Computer and Electrical Engineering (ICITACEE), 2014.

[13] Ricky Fajar Adiputra, Florentinus Budi Setiawan, "ROBOT ARM CONTROLLED BY MUSCLE TENSION BASED ON ELECTROMYOGRAPHY AND PIC18F4550", Proc. Of $20163^{\text {rd }}$ Int. Conf. on Information Tech., Computer, and Electrical Engineering (ICITACEE), 2016.

[14]Florentinus Budi Setiawan, Siswanto, "Electromyography (EM G) Signal Compression using Sinusoidal Segmental Model", Proc. of 2015 2nd Int. Conference on Information Technology, Computer and Electrical Engineering (ICITACEE), 2015.

[15] Analog Devices. 2003. "Low Cost Low Power Instrumentation Amplifier". One Technology Way.
[16] Kevin Eka Pramudita, F.Budi Setiawan, Siswanto, "Interface and display of Electromyography signal wireless measurements", $20141^{\text {st }}$ International Conference on Information Technology, Computer and Electrical Engineering (ICITACEE), 2014.

[17] Yohanes Oxa Wijaya, Florentinus Budi Setiawan, Siswanto, "Desain dan Implementasi Alat Pengukur Ketegangan Otot", Industrial Research Workshop and National Seminar (IRWNS), 2014 